\title{
Cognitive Presence and Effect of Immersion in Virtual Learning Environment
}

\author{
Ihor Katernyak ${ }^{1}$, Viktoriya Loboda ${ }^{2, *}$ \\ ${ }^{1}$ UDL System, Ivan Franko National University of Lviv, Ukraine \\ ${ }^{2}$ Department of Pedagogical Education, Ivan Franko National University of Lviv, Ukraine
}

Copyright $\mathrm{O} 2016$ by authors, all rights reserved. Authors agree that this article remains permanently open access under the terms of the Creative Commons Attribution License 4.0 International License

\begin{abstract}
This paper presents the approach to successful application of two knowledge management techniques community of practice and eLearning, in order to create and manage a competence-developing virtual learning environment. It explains how ' $4 \mathrm{~A}$ ' model of involving practitioners in eLearning process (through attention, actualization, attraction and action) can be exploited to overcome urgent knowledge gaps and master skills through both social and cognitive presence (cooperation and co-creation). In our case, each e-course or specific learning activity is viewed as an essential and topical event, which arouses certain emotions in the practitioners who take part in it, can feel immersed and get involved. $40 \%$ of e-course participants can feel arousal, 'drive' and have positive memorable eLearning experience, while almost every fourth practitioner can be 'actively immersed' in the virtual learning environment. The findings indicate that implementation of eLearning as event in the community of practice can be considered as successful approach to workplace learning.
\end{abstract}

Keywords Social and Cognitive Presence, Community of Practice, ELearning, Immersion, Virtual Learning Environment

\section{Introduction}

Academic mobility programs - on the one hand, and massive open online courses (MOOC) - on the other greatly expand access to educational products and services as well as to new experience in cross-culture learning environment. And universities are still looking for new approaches to the old challenge: how to accumulate industrial and public knowledge and how to become a platform where students can study in two dimensions: knowledge and practice.

Today universities face difficulties motivating learners to acquire knowledge that may be relevant to their 'distant' professional future, when everything around them is changing so dramatically and rapidly. And when it comes to workplace learning, it should be focused on the nearest professional future - "tomorrow" or even better "today", because not so distant prospect arouses greater interest and curiosity in learners-practitioners.

One of the reasons why people strain after gaining a different experience is usually described as follows: they seek to feel, experience something new that is different from their everyday activities and routine. Learners get a chance to experiment with their own identity, to play a different role [1]. People need advancement and diversification of their life through immersion in various meaningful activities and through gaining various experiences that stimulate (positive) emotions. Educators are aware of the fact that emotions have the power to open or close access to effective learning, memory, and the ability to make connections [2]. Besides, according to social constructivist approach, theoretical foundation of which were laid by such thinkers as Dewey, Vygotsky, Piaget, and Bruner, understanding or constructing a meaning is an active and continuous process based on learner's previous experience, which depends on learners taking responsibility to learn, and fits eLearning as 'learning among learners' [3], or collaborative learning. Recently, an updated theory of e-social constructivism has been proposed [4], taking into account the milieu of e-communications in general and eLearning in particular.

In this paper we present our approach to creating a learning environment at one's workplace where advanced knowledge and best practice are accumulated through eLearning and community of practice $(\mathrm{CoP})$, where everyone can be involved in constructing new knowledge and sharing expertise. Such environment should enable learners to demonstrate their readiness to apply and test new knowledge through relevant activities.

The art of knowledge management in such virtual learning environment (VLE) within the framework of a competence development strategy means the ability to run processes of constructing a meaning through collaboration and co-creation (cognitive presence). In a VLE, everyone can choose his/her own eLearning trajectory for achieving a 
specific learning objective: acquisition and development of required competences and mastering of professional skills. At the same time, effective knowledge management supports the state of flow in learners during the process of joint construction of meaning.

We view each learning activity as an event where participants might have fun and get memorable experience.

We were interested to find out how many participants experience the state of immersion and get memorable (positive) experience when they get involved in various types of eLearning activities. For this purpose, upon completion of each eLearning activity, the participants were asked to take part in a survey: they marked their own emotional state while carrying out a certain learning activity, on the proposed scale of the mental state, according to Mihály Csíkszentmihályi’s concept of flow [5].

\section{Background}

Ukrainian Distance Learning (UDL) System was founded as an eLearning operator in December 2000 by a consortium of universities, scientific and public academies, business schools and techno-parks. UDL mission is to develop policy and capacity of the consortium members using eLearning in their products and services. Since 2011, UDL System has successfully exploited knowledge management techniques (formation of communities of practice [6] and eLearning) for designing and conducting e-courses.

One of those policies for the Academy of Public Administration was to create the community of practice (CoP) in local development, where representatives of local government bodies are donors of public knowledge and best practice. Thus, within five years the CoP DESPRO (Decentralization project in Ukraine) was formed, which brings together today 3127 professionals - public servants of different levels from 25 regions of Ukraine -who share the topic of interest, deal with complex issues, are ready to advance their knowledge and experience as well as interact online.

Over time, more and more practitioners join this $\mathrm{CoP}$ in order to look for new solutions required by public reforms and their new professional competencies. This $\mathrm{CoP}$ as a target audience enables us to scale up our educational services provided 'just in time' for workplace. The provision of 'just in time' e-courses and trainings and, hence, the construction of knowledge 'today for today' is especially topical due to often amendments taking place in the Ukrainian legislation. Under such conditions public servants have urgent need to address the emerging tasks in their everyday activities.

So far, 30 e-courses (with total 80 learning activities) have been organized and conducted for the CoP participants, with the average number of 328 learners in each e-course. Furthermore, the prepared $\mathrm{CoP}$ is passionate for collective learning and is a perfect place for eLearning: we have created the market where we know what our users (customers) value the most, and we can provide them exactly with what they need, rather than focusing on achieving competitive advantage over other providers of educational services and attracting as many customers as possible.

Our e-courses are CoP-driven, i.e. they are developed in short order to address the emerging issues and practical tasks faced by the CoP participants. This is possible due to the flexibility of UDL System team and active involvement of experts and tutors. For e-courses, we use modular-based system where every module is a complete learning event. Each event has certain purpose (message), learning objectives, all necessary resources and types of activities, expected outcomes and their assessment. All modules have recommended time limits, though learning activities within modules are flexible. Every learning event has a defined level of challenge, and learners are informed about it and should be prepared and ready to overcome it using required support resources such as glossary, experts room (forum), e-sources etc. Modules can be either interrelated or independent, depending on the specific instructional design and curriculum.

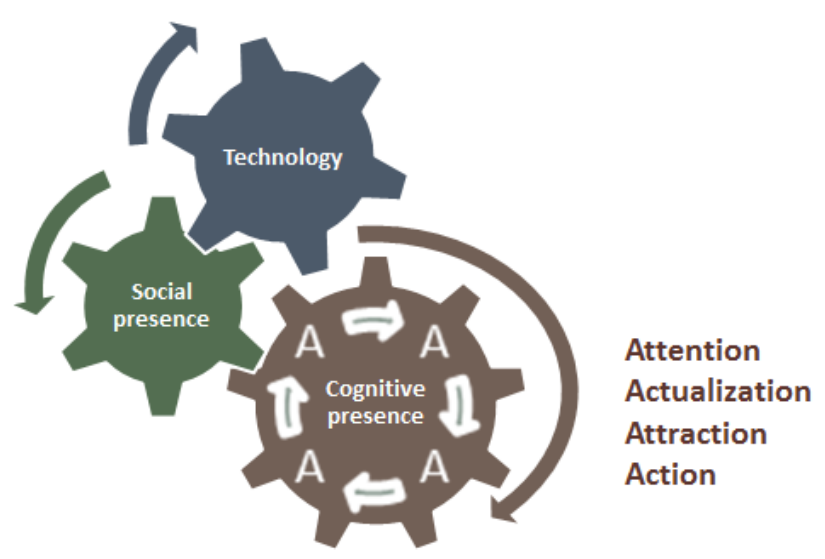

Figure 1. ' $4 \mathrm{~A}$ ' model

For running cognitive presence processes in the VLE, we apply our ' $4 \mathrm{~A}$ ' model (Figure 1), which describes four main stages in constructing the meaning: attention, actualization, attraction and action. This model is focused on guaranteeing cognitive presence of e-course participants during every learning event, where:

$1 \mathrm{~A}$ - drawing attention to a specific learning event (module), understanding its place in the curriculum and role in overall e-course outcomes;

$2 \mathrm{~A}$ - actualizing the need for participating in this event through evaluation of one's knowledge gap (to assess learners' readiness to perform - i.e., to overcome the specific level of challenge) and through setting achievable goals;

$3 \mathrm{~A}$ - attract: engaging learners in interaction with support resources (training materials, experts, tutors), which help them get ready to perform and be aware of how their performance will be evaluated; 
4A - act: being involved in learning activities (forums, assignments, project tasks, glossaries, choices, quizzes, tests and other activities possible in VLE) where learners demonstrate knowledge, understanding, mastered skills, generate ideas, ask questions, give feedback, analyze, synthesize and evaluate, i.e. act as subjects in the process of creativity, cooperation and co-creation.

Immersion in the VLE means complete social and cognitive presence of learners. When immersion takes place in a specific context, different subjective experiences are cumulated by learners and help them develop necessary competences, including idea generation, decision making, quick and adequate response to a nonstandard situation, communication, teamwork and supporting own identity.

Our previous investigation has demonstrated the importance of a well-chosen balance between tasks difficulty (level of challenge) and learners' ability to fulfill the tasks (level of knowledge and skills), which creates the situation of success where learners' active engagement in the learning activities can be achieved.

We have defined learners' immersion in a learning event - experience-based eLearning context - as the process where $\mathrm{CoP}$ participants get new experience, which is supported by their existing experience and which helps them contribute to the continuous development of their life competences.

Our goal was to transform learners' behavior in the VLE from passive absorption - through social and cognitive presence - to active immersion up to intellectual escapism in the virtual $\mathrm{CoP}$, when the community participants share experiences, generate ideas and construct meaning: new knowledge and skills. Memorable (positive) experience is gained when the eLearning event engages every learner and arouses certain strong emotions in him/her. Our recent benchmark in eLearning has been: over $40 \%$ of learners are actively involved and absorbed, and $23 \%$ of e-course participants experience the state of immersion.

\section{Forming the Community of Practice}

Formation of a $\mathrm{CoP}$ requires responsible attitude of each participant to the processes of information exchange and sharing experiences concerning urgent complex issues, and to one's professional development.

In this respect, we can refer to maxims of the Seven Sages as the unifying principles: Communicate with others $(O \mu$ orot $\chi \chi \rho \omega)$, Give what you have received $(\Lambda \alpha \beta \omega v$

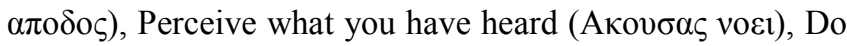
not nag at anyone $(\Psi \varepsilon \gamma \varepsilon \mu \eta \delta \varepsilon v \alpha)$, Act when you are sure (Гvovৎ $\pi \rho \alpha \tau \tau \varepsilon)$. I.e., each participant acts as a 'donor' of his/her unique experience in the community. In order to comply with the principle Know what you have learned

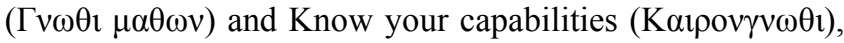
it is necessary to reflect on the lessons learned or heard, on the situation or action as well as on one's personal perspective, and to carry out self-evaluation. The principle of Using thy skills $(T \varepsilon \chi v \eta \chi \rho \omega)$ works for those who wants act as a generator of ideas, a leader of systemic changes.

CoP development is based on three pillars: knowledge, experience and passion for change (motivation). CoP becomes effective when participants share the aforementioned principles and are united as personalities, subjects of knowledge construction, professionals and practitioners.

In addition to information exchange and counseling, our idea was to add cognitive presence element to the CoP. That is why we offer the CoP participants to take part in e-courses and other eLearning events. Regular piloting and conduction of e-courses on various topics of common interest also encourages practitioners from all over the country to join the all-national community.

Whenever a pilot e-course is run, we as organizers have to deal with the following challenges: to avoid dropout of the e-course participants by providing them with space for their social presence, to guarantee their maximum cognitive presence, to engage the learners and enable each of them to be involved in various meaningful activities. At that stage of the community development is was found out that the key success factors for the formation of an effective VLE open for interaction included trust and reduction of psychological distance between the practitioners (learners) and experts (tutors).

The quality of each e-course has been guaranteed through the ' $4 \mathrm{~A}$ ' model, and its outcomes are measured in three dimensions: effectiveness, efficiency and comfort of social and cognitive presence of the participants. As a result, at least $90 \%$ of e-course graduates recommend their colleagues to join the $\mathrm{CoP}$. And when the $\mathrm{CoP}$ grew up to 2,000 members in 2013, it became viable and sustainable. Some members have left or become inactive, but even more have joined the community through the enrollment in new e-courses.

Today 3,127 participants take active part in the CoP, after 30 e-courses have been conducted since 2011, with the average number of 328 learners in each e-course. Speaking about the general profile of the CoP participants, $12 \%$ of them have more than 10 years of practical work experience, $15 \%$ - from 5 to 10 years of experience in the area of interest (viz. public administration), while other members are young, ambitious and passionate for changes. Around $70 \%$ of the CoP participants take part in e-courses on a regular basis. Thus, the critical mass of participants has been formed: they are skilled in eLearning tools and in the common topic of the community.

\section{Cognitive Presence in VLE}

In general, out of $328 \mathrm{CoP}$ participants (on average) who start an e-course, at least $70 \%$ get to the end, which is an acceptable rate for eLearning in workplace, and $60 \%$ of 
learners successfully complete it by receiving a passing grade and certificate. Usually, at the beginning of an e-course, we ask participants to define their expectations in terms of new knowledge and competences, and to explain how it corresponds to their professional growth. In order to actualize their need for specific knowledge or skills, we offer a self-test. Quite often, this self-test is a mandatory condition for starting an e-course.

At the same time, our expectation from each e-course is to trigger non-standard, creative and innovative thinking in participants through creation of such learning events, which are the momentum for change that require construction of new knowledge for decision-making and action. As a result, the learners are able develop competences, get new impressions and experiences.

The eLarning events involve both individual and team work and are focused on creating positive and meaningful learning experience in the participants. Upon completion of every learning activity, the participants mark their emotional and mental state using the proposed scale ranging from apathy, - through unrest, anxiety, boredom and relaxation, to control, excitement, joy and influx of ideas.

The latest analyzed e-course in Project Management is conducted annually, though every time it is modified according to the latest changes in the legislation and the conditions of the annual regional competition of projects and programs of local government.

In 2016, this course consisted of four modules and it was offered in a self-paced mode, accessible 24/7. Each participant had an opportunity to plan his/her own learning trajectory in terms of available resources and time. The participants could have access to the materials and tools of the next module or block only after all learning activities in the previous block were marked as completed (passed). If necessary, they were able to return back and have another attempt in order to improve the score. We suggest viewing the main types of activities offered in terms of learning domains and the learners' mental state and emotions.

\subsection{Quiz - for Remembering and Understanding}

Knowledge-based quizzes help us create a highly competitive environment from the start. Besides, the names of top ten participants with the highest score are automatically updated in the rating located on the home page of the e-course. Participants usually have two attempts and limited time to pass the quiz.

In the analyzed e-course, the learners were aware of the importance of this activity because they were further divided into groups according to the results of the quiz. $27 \%$ of the participants felt worry and unrest, which means that the level of challenge was quite high for them, while $36 \%$ were strongly motivated and could feel excitement and zeal to satisfy their emerged learning needs (Figure 2).

The use of constantly updated ratings - top 10 or 20 highest grades for each course activity (quiz, test or assignment) throughout the e-course - supported the competitive spirit between individual learners and groups. Besides, the e-course participants could see their own progress in the grade book and in the section of their course completion status.

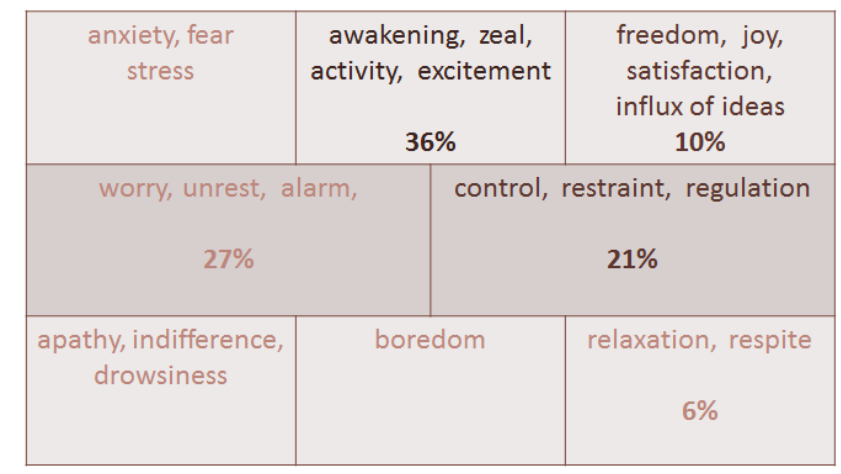

Figure 2. Mental state of the e-course participants (in \%) while taking ‘quiz' activity

\subsection{Task - for Understanding and Application}

In addition to quizzes, the participants were offered individual tasks where they had to understand the subject and master their skills in interactive context: successful task performance depended both on personal presentation and on well-established relation with other participants.

The main focus was made on providing social presence, supporting learners' motivation and giving each of them an opportunity for cognitive presence: getting acquainted with the e-course content, check one's understanding of the issue by fulfilling individual tasks and using the acquired knowledge and skills in practice.

According to the participants, the majority of them (33\%) followed certain regulations while fulfilling the tasks, so they kept the process under control and felt quite confident. Though for $39 \%$ of the participants $(15 \%$ feeling fear + $24 \%$ feeling worry) the level of challenge was too high, and they were stressed, worried and felt unrest. Only $4 \%$ of the participants found the tasks to be too easy, so they felt relaxed (Figure 3).

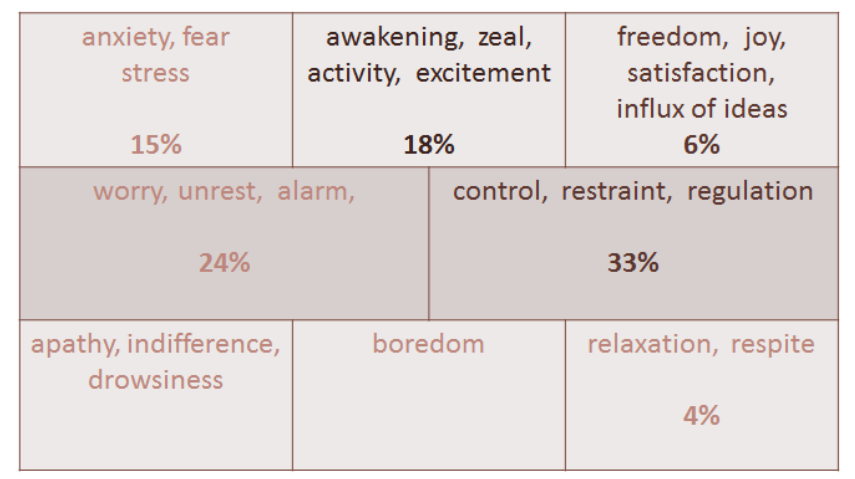

Figure 3. Mental state of the e-course participants (in \%) while performing 'task' activity 


\subsection{Project Work - for Analyzing, Evaluating and Creating}

The e-course participants had an opportunity to carry out a project. First they were offered a case, which they had to analyze using different methods, to find necessary and sufficient factors for designing a solution and to write the project, using a given template.

The participants felt high responsibility for successful performance of this activity because they were aware of the high weight of its score in the general course grade. Besides, they knew that the best projects would be selected and published on the home page of the course together with tutors' feedback: so that others could get acquainted with their work and learn from each other.

Thus, we could observe both inner and outer motivation of the participants that is the driving force for their eLearning. More than half of all learners felt confident while carrying out the project task because they were aware of the criteria against which the project was to be evaluated by experts and had the template to follow. For $27 \%$ of the participants ( $3 \%$ feeling fear and stress $+24 \%$ feeling worry and unrest) it was a difficult task (Figure 4).

Generally, the use of case method in eLearning requires effective communication system, which includes communication within the team that can be guided by a facilitator, and communication with an expert. A facilitator or tutor has to create an environment where every team member feels free to be involved in the activity and can make individual contribution in the teamwork.

When we use the case method, our ultimate goal is to create the environment for meaningful communication and co-creation, which is usually achieved through the introduction of certain learning events: teamwork on a project using Wiki or group assignments.

\begin{tabular}{|c|c|c|}
\hline $\begin{array}{c}\text { anxiety, fear } \\
\text { stress } \\
\\
3 \%\end{array}$ & $\begin{array}{c}\text { awakening, zeal, } \\
\text { activity, excitement } \\
6 \%\end{array}$ & $\begin{array}{c}\text { freedom, joy, } \\
\text { satisfaction, } \\
\text { influx of ideas } \\
6 \%\end{array}$ \\
\hline $\begin{array}{r}\text { worry, unrest, a } \\
24 \%\end{array}$ & control, & $\begin{array}{l}\text { estraint, regulation } \\
55 \%\end{array}$ \\
\hline $\begin{array}{c}\text { apathy, indifference, } \\
\text { drowsiness }\end{array}$ & boredom & $\begin{array}{c}\text { relaxation, respite } \\
6 \%\end{array}$ \\
\hline
\end{tabular}

Figure 4. Mental state of the e-course participants (in \%) while performing 'project' activity

\subsection{Online Workshop - from Understanding to Action}

We used a challenging online workshop in the e-course in order to promote understanding of the key concepts and rules among learners, to help them formulate questions and/or problems and generate ideas for solution.

The workshop included a series of assignments and tests with open-ended questions. They encouraged learners to delve into the essence of the issue and provoked collaboration and co-creation among the participants. The suggested situation was very close to the real-life work conditions. And the participants had to find the best possible solution within certain timeline and using limited resources, and - what is even more important - to act, try out and implement this solution in practice.

Due to successful organization and combination of individual and teamwork, we have achieved the result when $41 \%$ of the e-course participants stated that they had the feeling of arousal and 'drive' (awakening, excitement), while $23 \%$ of the participants felt freedom, joy, sense of satisfaction, influx of new ideas (Figure 5).

\begin{tabular}{|c|c|c|}
\hline $\begin{array}{c}\text { anxiety, fear } \\
\text { stress } \\
9 \%\end{array}$ & $\begin{array}{c}\text { awakening, zeal, } \\
\text { activity, excitement }\end{array}$ & $\begin{array}{c}\text { freedom, joy, } \\
\text { satisfaction, } \\
\text { influx of ideas } \\
\mathbf{2 3 \%}\end{array}$ \\
\hline \multicolumn{2}{|c|}{$\mathbf{4 1 \%}$} & $\mathbf{2 2 \%}$ \\
\hline $\begin{array}{c}\text { worry, unrest, alarm, } \\
\text { apathy, indifference, } \\
\text { drowsiness } \\
1 \%\end{array}$ & control, restraint, regulation \\
\hline
\end{tabular}

Figure 5. Mental state of the e-course participants (in \%) while taking part in online workshop

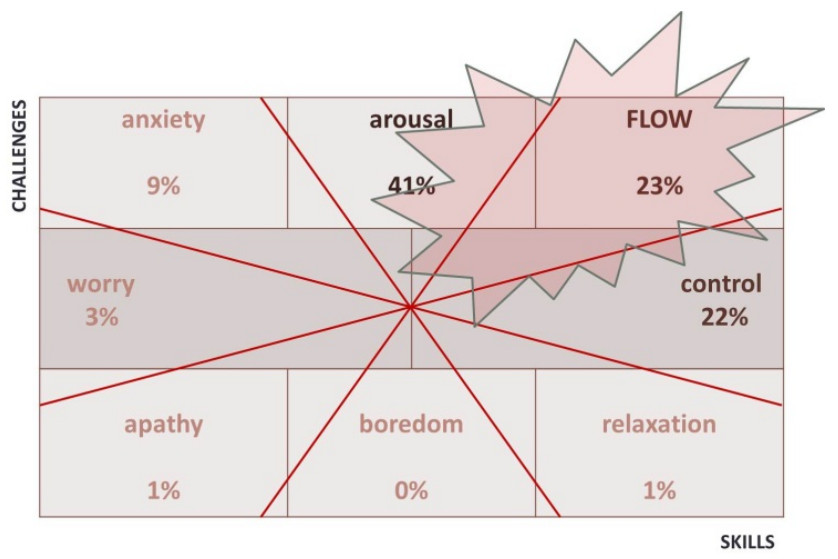

Figure 6. Achieving the state of flow while taking part in the online workshop

Having analyzed the results of the final survey of the CoP participants in the online workshop of the e-course, we can state that their immersion in the process of eLearning means entering highly focused mental state and living the 'second life' - flow. Besides, we could observe the optimal balance between the level of challenge of the assignments and the level of knowledge and skills of the participants who were ready to overcome this challenge successfully (Figure 6).

Thus, our latest success in the organization of e-courses for 300-400 learners has ensured that almost every fourth learner can experience complete (active) immersion. In our 
latest e-course, $64 \%$ of learners ( $41 \%$ feeling arousal $+23 \%$ feeling flow) had the feeling 'drive' and got positive memorable learning experience, as well as the $22 \%$ of them had their learning progress under control and felt secure by following regulations. The statistics report demonstrated from 5,000 to 7,000 hits in the e-course web-site per day, including weekends, while most participants spent up to 2 hours in the e-course daily [7].

Active immersion (the upper rightward part of the table) of the CoP participants in the VLE environment for individual and joint construction of knowledge, with a focus on the nearest future, using real-life case studies and meaningful learning events, can guarantee the development of life competences necessary for performing high-quality professional functions. Thus, the combination of two knowledge management techniques - $\mathrm{CoP}$ and eLearning can provide the effect of immersion in VLEs.

\section{Conclusions}

The findings indicate that the effect of immersion of every fourth learner in VLE can take place during successful e-course (event) in the CoP when industrial/public knowledge, best practice and cultural diversity are located in one place - VLE.

The success of e-courses in the CoP is defined by the following factors:

- objectives of an e-course offered within the CoP meet the needs of the community participants; learning activities are demonstration of participants' understanding of the subject and awareness of best practice, construction of knowledge and its application in practice; tasks corresponds to the level of competence of the $\mathrm{CoP}$ in general and the ability of every participant to successfully fulfill tem;

- monitoring system is used by learners for evaluating their learning progress and for supporting competitive environment;

- social presence where everyone has high degree of awareness of other people in the community and has right to be involved in various learning events, where the involvement of everyone is fairly evaluated; everyone can ask questions, and every answer will be 'heard'; everyone has the right to speak, to share own experiences;

- cognitive presence of each participant, which encourages collaboration, creativity, idea generation, development of new solutions and finding ways to act and implement them.

Learners' behavior in VLE, which follows the ' $4 \mathrm{~A}$ ' model (attention - by needs in knowledge and experience, actualization - by focusing on learning objectives and being free to build one's own learning trajectory, attraction - by involving learners in sharing experience, cooperation and co-creation, and action - by overcoming challenges in tasks and problem-solving in case studies), drives their motivation to be actively engaged in knowledge construction.

Thus, we offer every type of learning activity in VLE to be viewed as an event that arouses specific emotions in learners, viz. flow, arousal, control, anxiety, relaxation, worry, boredom, apathy, which should be included as indicators of e-course evaluation form. And the achievement of positive emotions (esp. flow and arousal) in learners guarantees their immersion and ability to share the acquired knowledge and practice.

\section{REFERENCES}

[1] A. F. Firat, N. Dholakia. Consuming people: from political economy to theatres of consumption. London: Routledge, 96-97, 1998.

[2] P. L. Vail. The Role of Emotions in Learning. Great Schools, 2010. Online available from http://www.greatschools.org/par enting/teaching-values/the-role-of-emotions-in-learning.gs?c ontent $=751$ \&page $=2$

[3] A. Koohang, L. Riley, T. Smith, J. Schreurs. E-Learning and Constructivism: From Theory to Application. Interdisciplinary Journal of E-Learning and Learning Objects, Vol. 5, 2009

[4] J. Salmons. E-Social Constructivism and Collaborative E-Learning, In: J. Salmons and L. Wilson (Eds.). Handbook of Research on Electronic Collaboration and Organizational Synergy, 280-294, 2009.

[5] M. Csíkszentmihályi. Flow: The psychology of optimal experience. New York, NY: Harper Perennial, 2008.

[6] J. Lave, E. Wenger. Communities of practice: learning, meaning, and identity. Cambridge University Press, 1998.

[7] O. Garnets, I. Katernyak, V. Loboda, M. Kulya. Knowledge management and the effect of immersion in virtual learning environments, Proceedings of Global Learn 2016. Association for the Advancement of Computing in Education (AACE), 234-239, 2016. 